\section{Ape and human similarities can be deceptive}

SIR — In his Essay 'Darwin's last laugh' (Nature 460, 175; 2009), Frans de Waal suggests that ape vocalizations are homologous to human laughter, which they could be - but that does not necessarily imply that apes have a sense of humour. Adaptive divergence could be at play, making humans the ones who get the jokes.

Darwin's singular contribution to the issues raised by de Waal is that, in spite of universal appreciation for the behavioural similarities between humans and other animals, these continuities can be divided into two classes. The first is a symbolic, or literary, relationship, familiar to us through Aesop: the ant is industrious, the fox is clever. The second is the result of a shared biological history, or common ancestry. Our scientific interest in the apes is presumably based on the expectation that the similarities we can identify between them and us are principally of the second type. Although critical to de Waal's argument, this type of overlap is, unfortunately, much easier to assume than to demonstrate.

The circumstances in which similarities between chimps and humans manifest often indicate the opposite - that the behaviours are not directly homologous and are being overenthusiastically interpreted. For example, infanticide by chimps is carried out by non-relatives (for reasons only they know) whereas in humans it may be carried out by the mother, or by someone acting on her behalf, mainly for cultural, social or economic reasons. In one species, the act is aggressive, violent and often cannibalistic, with no indication of the remorse that can accompany the act in the other species.

And although our feet are homologous to ape feet, the chimp's foot is principally adapted for grasping and the human foot to weightbearing. They are similar, and are descended from a common ancestral structure, but they are by no means the same.

A genuine Darwinian approach to primate behaviour may have to acknowledge that the brains of apes (and their capabilities) may simply be different from our own, like their feet. Evolution, after all, is the production of difference. If one scholar acknowledges the adaptive divergence that has occurred between a human and a chimp over 7 million years or so of separation, and another insists that they are the same, then who is really in denial of evolution?

Jonathan Marks Department of Anthropology, University of North Carolina at Charlotte, Charlotte, North Carolina 28223, USA e-mail:jmarks@uncc.edu

\section{Speed of reporting isn't the issue when your work is scooped}

SIR - In your Editorial 'How to stop blogging' (Nature 460, $152 ; 2009)$, you urge the conference community to be clear from the outset about whether their meetings are 'open' or 'closed' with respect to the informal dissemination of their content. In my view (as a scientist and a blogger, http:// tinyurl.com/mf8ynx), this risks treating early adopters of new communication technologies as scapegoats.

A few years ago, interested conference participants might have stood in front of a poster and sketched the figures for themselves; more recently, they might have snapped a digital photo while the presenter's back was turned. Key information could always be relayed by a swift phone call back to their laboratories. Now people can also tweet to the lab or the wider 'tweetersphere'.

We present information in order to disseminate it and enhance our reputations. Whether this occurs within weeks, days or minutes is just a question of scale.

If a competitor can scoop me by tweeting or blogging my data only a few days or hours faster than he or she would have done by simply coming to my poster and taking ideas back to the laboratory, then the problem clearly lies with my own inability to conclude and publish my research - not in the progress of technology.

For the most part, the use of this technology is limited to sharing information with likeminded individuals. The nature of the conference has not changed, only the mindset of the participants.

Ian M. Brooks Biomedical Informatics Unit, University of Tennessee Health Science Center Clinical and Translational Science Institute, Memphis, Tennessee 38163, USA e-mail: ibrooks1@utmem.edu

Readers are welcome to comment at http://tinyurl.com/kkfe6e

\section{European bodies can help to tackle TB worldwide}

SIR - We welcome your Editorial plea ('Orphan giant' Nature 459, 1034; 2009) for stronger advocacy for tackling tuberculosis (TB), a shared global strategy and increased commitment to research and innovation. The emerging threat of drug-resistant TB in Europe, highlighted in a recent report from the European Academies Science Advisory Council (EASAC; www.easac.eu) could be an opportunity to bring European Union (EU) publichealth objectives to bear on a shared global strategy.

EASAC was formed by the national science academies of EU member states to provide advice to policy-makers. Its report indicates that the EU has failed so far to respond adequately to the global TB threat, despite now being on the frontline for infection control. There is still an opportunity for strategic

leadership: the EU is in a good position to draw on its considerable strengths in science, to develop effective coordinated public-health capabilities and to contribute to solving the problem on a global scale.

The report recommends, for example, that the EU should improve its procedures for collecting, reporting and using its own TB-surveillance data. To help understand the molecular determinants of virulence and resistance, standardized characterization of pathogen strains and their drug sensitivity should be linked into user databases of genetic and clinical information. Better EU funding models for research and innovation should eventually generate new health-care products and services.

The domestic public-health objectives for the EU can be directly aligned with global policy requirements. For example, policy-makers worldwide need to extend the 'advanced market commitment' - under which governments and other sponsors pay in advance for development of vaccines - to cover TB diagnostics, drugs and vaccines. However, to avoid repetition of previous problems caused by lack of coordination among multiple initiatives, there must also be more effective interaction among EU institutions, intergovernmental and non-governmental organizations.

Robin Fears EASAC, The Royal Society, 6-9 Carlton House Terrace, London SW1Y 5AG, UK e-mail: robinfears@aol.com Alimuddin Zumla Centre for Infectious Diseases and International Health, University College London Medical School, London W1T 4JF, UK Volker ter Meulen EASAC and German Academy of Sciences Leopoldina, Postfach 110543, 6019 Halle (Saale), Germany

Contributions to this page may be sent to correspondence@nature. com. Please see the Guide to Authors at $h$ ttp://tinyurl.com/373jsv 